\title{
Taste Familiarity Is Inversely Correlated with Arc/Arg3.1 Hemispheric Lateralization
}

\author{
Sharon Inberg, ${ }^{1}$ Alina Elkobi, ${ }^{1}$ Efrat Edri, ${ }^{2}$ and Kobi Rosenblum ${ }^{1,2}$ \\ ${ }^{1}$ Sagol Department of Neurobiology, and ${ }^{2}$ Center for Gene Manipulation in the Brain, University of Haifa, Haifa 30905, Israel
}

Biochemical, electrophysiological, and imaging studies suggest that the anterior part of the insular cortex (IC) serves as primary taste cortex, whereas fMRI studies in human propose that the anterior IC is also involved in processing of general novelty or saliency information. Here, we compared activity regulated cytoskeleton associated protein (Arc)/Arg3.1 protein levels in the rat IC following administration of familiar versus novel tastes. Surprisingly, there was no correlation between novel taste and Arc/Arg3.1 levels when measured as the sum of both left and right insular cortices. However, when left and right IC were examined separately, Arc/Arg3.1 level was lateralized following novel taste learning. Moreover, Arc/Arg3.1 lateralization was inversely correlated with taste familiarity, whereas the high lateralization of Arc/Arg3.1 expression observed following novel taste learning is reduced proportionally to the increment in taste familiarity. In addition, unilateral inhibition of protein synthesis in the IC had asymmetrical effect on memory, inducing strong memory impairment similarly to bilateral inhibition or memory preservation, indicating that hemispheric lateralization is central for processing taste saliency information. These results provide indications, at the gene level of expression, for the role of IC lateralization in processing novel taste information and for the asymmetrical contribution of protein synthesis in each hemisphere during memory consolidation.

\section{Introduction}

Detection of novelty occurs at an early stage of memory acquisition and is required for the encoding of incidental memories into long-term storage as engrams (Tulving et al., 1996). The insular cortex (IC) in humans plays a prominent role in high-order mental processes and body state assessment, as well as in attention processes. Moreover, the IC is strongly involved in saliency detection and deviation embedded in a stream of continuous stimuli (for review, see Menon and Uddin, 2010).

The gustatory cortex (GC) which resides within the IC is critically involved in taste memory consolidation (for review, see Gal-Ben-Ari and Rosenblum, 2011), maintenance (Shema et al., 2007), and retention (Stehberg and Simon, 2011). Accumulated data have revealed that novel taste learning is associated with many biochemical changes in the GC which subserve taste consolidation in rodents, including changes in cholinergic activity (Miranda et al., 2003), tyrosine phosphorylation of the NR2B subunit of the $N$-methyl D-aspartate receptors, (Rosenblum et al., 1997; Barki-Harrington et al., 2009), activation of extracellular regulated kinase I/II (ERK I/II) and Elk-1 (Berman et al., 1998), and activation of the mTOR pathway (Belelovsky et al.,

\footnotetext{
Received Feb. 20, 2013; revised May 5, 2013; accepted May 30, 2013.

Author contributions: S.I. and K.R. designed research; S.I., A.E., and E.E. performed research; S.I. and K.R. analyzed data; S.I. and K.R. wrote the paper.

This work was supported by European Union Seventh Framework Program EUROSPIN (Contract HEALTH-F22009-241498) and the German-Israeli Foundation DIP (R03971/1-1) for KR. We thank laboratory members of K.R., specifically Dr. David Levitan, Dr. Shunit Gal-Ben Ari, and Karen Lavi for their support, and Dr. Paul Skehel for critical reading of the paper.

The authors declare no competing financial interests.

Correspondence should be addressed to Kobi Rosenblum, Sagol Department of Neurobiology, University of Haifa, Haifa 31905, Israel. E-mail: kobir@psy.haifa.ac.il.

DOI:10.1523/JNEUROSCI.0801-13.2013

Copyright $\odot 2013$ the authors $\quad 0270-6474 / 13 / 3311734-10 \$ 15.00 / 0$
}

2009). In contrast, changes in CREB activity have not been detected (Yefet et al., 2006). There is, however, limited information about the GC as part of a brain network involved in novel taste learning and saliency processing.

Immediate early genes (IEGs) are well known molecular markers for cellular activation and synaptic plasticity. IEGs are used frequently to delineate active cells and neuronal populations at single-cell resolution following learning and memory, and may therefore be the link between changes in neuronal circuit activity and intracellular molecular mechanisms (Guzowski et al., 2005; Okuno, 2011).

The effector IEG activity regulated, cytoskeleton-associated protein (Arc)/Arg3.1 is used as a marker of neural activation and synaptic plasticity. Arc is involved in $\alpha$-amino-3-hydroxy-5methyl-4-isoxazolepropionic acid receptor (AMPA-R) endocytosis by interacting with two core endocytic proteins, endophilin and dynamin (Chowdhury et al., 2006). In addition to synaptic plasticity, Arc/Arg3.1 knock-out mice show severe impairment in long-term memory performance including disrupted ability to form long-term memory for conditioned taste aversion (CTA; Plath et al., 2006).

The involvement of lateralization in memory consolidation is not well documented; moreover, the assumption underlying the majority of studies addressing the molecular and cellular mechanisms of learning and memory is that two sides of the relevant brain region equally contribute to the acquisition, maintenance, and retrieval of the memory trace.

In humans, the hippocampus showed lateralized involvement in representation of a navigation task with complementary contribution of each side to the episodic memory (Iglói et al., 2010). In this study, we analyzed the differential contribution of the left and right GC hemispheres as well as their coordination to novel 
taste memory consolidation by using $\operatorname{Arc} / \operatorname{Arg} 3.1$ protein as a marker of circuit activity and synaptic plasticity.

\section{Materials and Methods}

\section{Animals}

Wistar Hola male rats, 8- to 14-weeks-old, were used in all experimental procedures. The rats were caged individually at the beginning of the behavioral session and placed in a $12 \mathrm{~h}$ light/dark cycle at constant temperature of $22^{\circ} \mathrm{C}$, with food and water available ad libitum, except during the experiment, when animals were water deprived $24 \mathrm{~h}$ before daily ration of fluids and between daily rations delivered through pipettes throughout the experiment. All experiments were performed in the light phase. Animals were handled according to approved protocols and animal welfare regulations of the Institutional Animal Care and Committee of the University of Haifa. Protocols were also in accordance with the guidelines laid down by the Israeli National Institutes of Health.

\section{Behavior}

For all behavioral paradigms, animals were water restricted and housed separately in a new cage $24 \mathrm{~h}$ before beginning of pipette drinking schedule. Food was available ad libitum throughout the experiment.

\section{Incidental taste learning}

Following separation from grouped home cages, rats were subjected to water restriction regime and were trained to drink their daily $20 \mathrm{ml}$ of water from two $10 \mathrm{ml}$ plastic pipettes for the duration of $20 \mathrm{~min}$ for 3 consecutive days. Following training, animals were divided into three groups: water and two novel tastes: $0.1 \%$ saccharin and $0.3 \%$ sodium chloride diluted in tap water (see Fig. 1a). Consumption of at least $10 \mathrm{ml}$ is required to achieve learning (Merhav and Rosenblum, 2008). Animals which did not reach the minimum amount in 5 additional minutes were excluded from the experiment.

Two different familiarity paradigms for $0.1 \%$ saccharin were used (see Fig. 3a):

Two times saccharin. The animals drank $20 \mathrm{ml}$ of water for $20 \mathrm{~min}$ from pipettes in the $2 \mathrm{~d}$ after separation. At the fourth day they were exposed to $0.1 \%$ saccharin, $20 \mathrm{ml}$ for $20 \mathrm{~min}$ by pipette and killed $1 \mathrm{~h}$ after the end of the drinking session on the fifth day.

Twenty-five days of saccharin. Saccharin $(0.1 \%)$ was available ad libitum from a bottle for $21 \mathrm{~d}$ in a grouped cage. Animals were then separated to individual cages and allowed access to $0.1 \%$ saccharin from pipette restricted to $20 \mathrm{ml}, 20 \mathrm{~min}$ per day for $3 \mathrm{~d}$. On the 25 th day the animals drank $0.1 \%$ saccharin from a pipette and were killed $1 \mathrm{~h}$ after the end of the drinking session.

\section{Conditioned taste aversion and anisomycin injections}

Following separation from grouped home cage, GC cannulated rats were subjected to the water restriction regime and were trained to drink their daily $20 \mathrm{ml}$ of water from two $10 \mathrm{ml}$ pipettes for a duration of $20 \mathrm{~min}$ for 3 consecutive days.

On the fifth day, the conditioning day, the animals were injected with $100 \mu \mathrm{g}$ anisomycin or vehicle into the GC. Animals were divided into 4 groups: (1) bilateral anisomycin injection, (2) bilateral saline injection, (3) anisomycin to left hemisphere and saline to right hemisphere, and (4) anisomycin to right hemisphere and saline to left hemisphere. Twenty minutes later they were allowed to drink the $0.1 \%$ saccharin solution from pipettes for $20 \mathrm{~min}$, and $40 \mathrm{~min}$ following the cessation of the drinking period they were injected with $\mathrm{LiCl}$ to the abdominal region. To recover, the animals drank water in the subsequent $2 \mathrm{~d}$ and on the third day after CTA they underwent a multiple-choice test in which they were offered two pipettes, each containing $5 \mathrm{ml}$ of saccharin and two pipettes, each containing $5 \mathrm{ml}$ of water. To measure the aversive memory, aversion index was calculated as follows $[\mathrm{ml}$ water/( $\mathrm{ml}$ water $+\mathrm{ml}$ saccharin $)]$.

\section{Surgical procedure}

Rats were anesthetized with equithesin $(0.45 \mathrm{ml} / 100 \mathrm{~g} ; 2.12 \% \mathrm{w} / \mathrm{v}$ $\mathrm{MgSO}_{4}, 10 \% \mathrm{v} / \mathrm{v}$ ethanol, $39.1 \% \mathrm{v} / \mathrm{v}$ propylene glycol, $0.98 \% \mathrm{w} / \mathrm{v}$ sodium pentobarbital, and $4.2 \% \mathrm{w} / \mathrm{v}$ chloral hydrate) and restrained in a stereotactic apparatus (Stoelting). Guide stainless-steel cannulae (23 gauge) were implanted bilaterally into the GC (anterior posterior, $1.2 \mathrm{~mm}$; dorsal-ventral, $6.5 \mathrm{~mm}$; lateral, $5.5 \mathrm{~mm}$ ). The cannulae were positioned using acrylic dental cement and secured by two skull screws. A stylus was placed in the guide cannulae to prevent clogging. After surgery, animals were allowed to recover for 1 week, before being subjected to experimental manipulations.

\section{Microinjection}

The stylus was removed from the guide cannula and a 28-gauge injection cannula, extending from the tip of the guide cannula, was carefully placed. The injection cannula was connected via PE20 tubing to a Hamilton microsyringe, driven by a microinjection pump (CMA/100; Carnegie Medicin), $1 \mu \mathrm{l}$ of anisomycin $(100 \mu \mathrm{g} / \mu \mathrm{l})$ or vehicle at a rate of $1 \mu \mathrm{l} / \mathrm{min}$ was injected. Following injection, the injection cannula was left for an additional $30 \mathrm{~s}$ before withdrawal, to minimize liquid retraction.

\section{Immunohistochemistry}

Tissue fixation. One hour following the cessation of drinking session, the animals were anesthetized by injection of pentobarbital $(10 \mathrm{mg} / 100 \mathrm{~g})$ and transcardially perfused with $\sim 150 \mathrm{ml}$ of cold $0.01 \mathrm{M}$ PBS solution, followed by $150 \mathrm{ml}$ of $4 \%$ paraformaldehyde in $0.01 \mathrm{M}$ PBS containing $5 \%$ sucrose. Brains were excised and postfixed in fixative solution containing $30 \%$ sucrose and $1 \%$ paraformaldehyde in $0.01 \mathrm{~m}$ phosphate PBS for $96 \mathrm{~h}$ at $4^{\circ} \mathrm{C}$. After postfixation, brains were covered with aluminum foil and frozen in $-80^{\circ} \mathrm{C}$ until sectioning by microtome.

Arc/Arg3.1 immunohistochemistry procedure. Coronal $40 \mu \mathrm{m}$ brain sections were sliced with a cooled microtome (Leica, SM2000R). For each animal four coronal brain slices of $40 \mu \mathrm{m}$ were taken from +1.3 to +0.8 anterior to bregma alternately (covering in total $500 \mu \mathrm{m}$ ). The left hemisphere was distinguished from the right by making a small pinhole in the left motor cortex.

Slices were washed twice with $0.01 \mathrm{M}$ PBS, and then blocked for $3 \mathrm{~h}$ at room temperature (RT) with $0.01 \mathrm{M}$ PBS containing $0.5 \%$ Triton X-100 and $1.2 \%(\mathrm{w} / \mathrm{v})$ of normal goat serum. Sections were then incubated overnight at RT with the Arc/Arg3.1 primary antibody (Santa Cruz Biotechnology, H300 rabbit polyclonal antibody, sc-15325) diluted 1:100 in $0.01 \mathrm{~m}$ PBS.

After 3 washes in $0.01 \mathrm{~m}$ PBS, Alexa488 anti rabbit secondary antibody in 1:200 dilution and $0.2 \%(\mathrm{w} / \mathrm{v})$ normal goat serum in $0.01 \mathrm{M} \mathrm{PBS}$ (Invitrogen) were applied for $1.5 \mathrm{~h}$ at RT. After two PBS $0.01 \mathrm{M}$ washing steps nuclei were stained by incubating the sections with Hoechst 33258 diluted 1:5000 in PBS 0.01 M. Sections were mounted onto Super Frostcoated slides with Slow Fade antifade medium (Invitrogen). Slides were kept in the dark at $4^{\circ} \mathrm{C}$ before image acquisition and analysis.

\section{Image analysis}

Manual image analysis was performed using CellP (Olympus) program.

IX81 inverted Olympus microscope equipped with two fluorescent filter sets, DAPI (ex. 360/40, em.460/50) and GFP (ex.480/20, em. 510/ 20 ) was used for imaging. For each animal nine images at $\times 20$ magnification were taken from left and right hemisphere from four coronal slices, total 18 images per slice, and 72 per animal. The GC was divided to nine regions in dorsal-ventral axis-agranular insular cortex (AI), dysgranular insular cortex (DI), granular insular cortex (GI), and in the lateral axis for cortical layers $1-6$ as illustrated in Figure $1 b$, with three images taken per region in each hemisphere, in three layer depths.

Defined ROI of was imposed on each picture. Number of somatic/ nuclear Arc/Arg3.1-positive cells was counted per ROI after defining manually the threshold for signal above the background. The threshold of positive immunoreactive staining was set by the experimenter and was manually determined as cellular staining darker than the surrounding. All positive targets in the ROI were detected and counted automatically, excluding noncellular irregularities in the background staining and/or particles smaller than 100 pixels. Mean number of Arc/Arg3.1-expressing cells per ROI was calculated for the total two hemispheres, and for the left hemisphere and right hemisphere separately for each animal.

\section{Western blotting}

Tissue homogenization. Twenty minutes or $1 \mathrm{~h}$ following the cessation of the drinking session, the GC was dissected out with discrimination be- 


\section{a}

novel $0.1 \%$ saccharin

Day 1:
separation of
animals

after $1 \mathrm{hr}$

or 20 minutes b

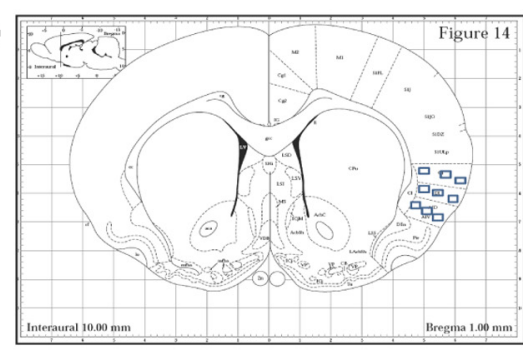

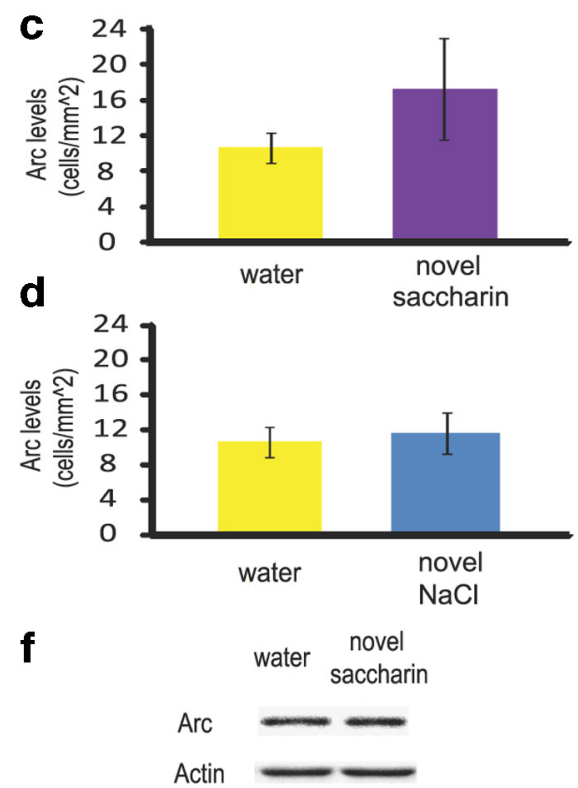

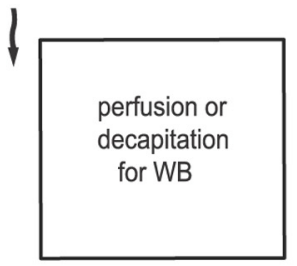

groups:

water, $0.1 \%$

saccharin

$0.3 \% \mathrm{NaCl}$

\section{e}

water

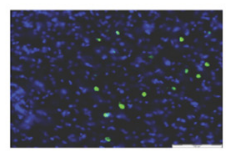

novel saccharin

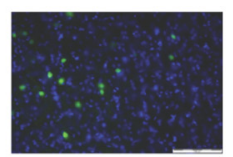

novel

$\mathrm{NaCl}$

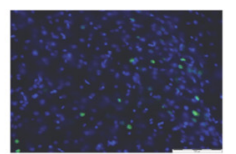

\section{g}

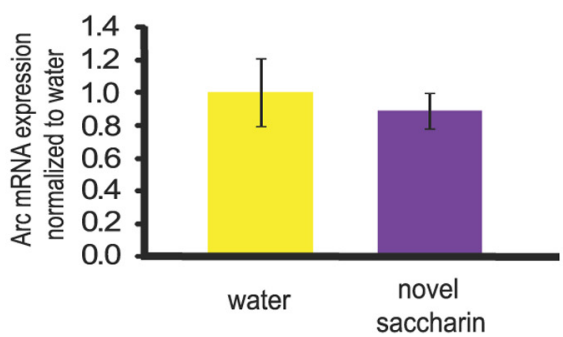

h

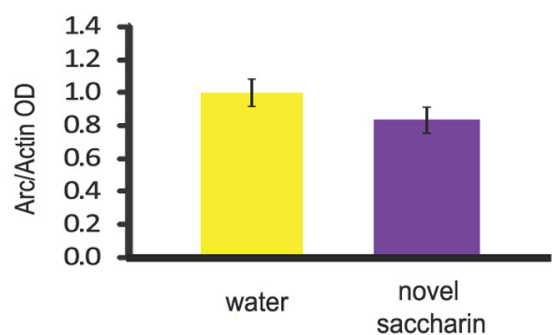

water water sacc.sacc.
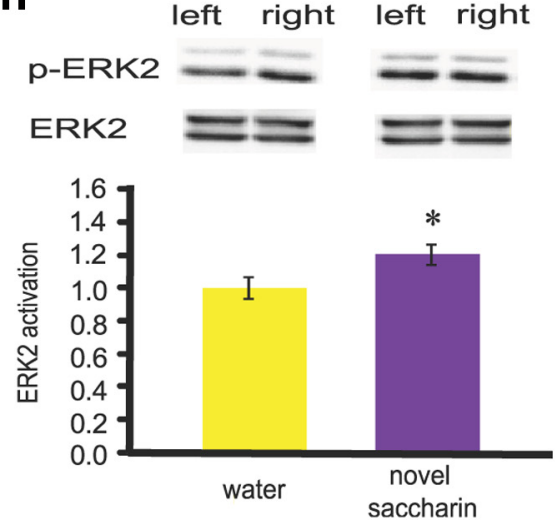

Figure 1. Bi-hemispheric Arc/Arg3.1 is not modulated in the gustatory cortex after novel taste learning. $\boldsymbol{a}$, Schematic representation of the behavioral paradigm of novel taste learning. $\boldsymbol{b}$, Rat coronal brain section containing the gustatory cortex with illustration of the nine sampling rectangles. $\boldsymbol{c}, \boldsymbol{d}$, Arc/Arg3.1 protein levels remain stable $1 \mathrm{~h}$ following novel taste learning for combined left and right hemispheres, as measured by immunohistochemistry. Rats drank $0.1 \%$ saccharin $(n=8)$ or $0.3 \% \mathrm{NaCl}(n=3)$ as a novel taste, or water $(n=7)$ as a familiar taste. $p>0.05$. $\boldsymbol{e}$, Immunofluorescence representative images (blue, Hoechst nuclear staining; green, Arc/Arg3.1 protein). Scale bar, $100 \mu \mathrm{m}$. $\boldsymbol{f}$, Arc/Arg3.1 protein levels remain stable $1 \mathrm{~h}$ following novel taste learning for combined left and right hemispheres, as measured by Western blot. Rats drank $0.1 \%$ saccharin $(n=7)$ or water $(n=7)$ as a familiar taste. Top, Representative immune-blots of Arc/Arg3.1and Actin. $p>0.05 . \boldsymbol{g}$, Arc mRNA levels remain stable $1 \mathrm{~h}$ following novel taste learning for combined left and right hemispheres, as measured by qRT-PCR. $p>0.05 . \boldsymbol{h}$, When combining the volume of each band (area of the band ${ }^{*}$ optical density) for left and right, ERK was activated 20 min following novel taste learning, as measured by Western blot. Rats drank $0.1 \%$ saccharin ( $n=$ $5)$ or water $(n=5)$ as a familiar taste. Top, Representative immune-blots of $p$-ERK and ERK proteins. ${ }^{*} p<0.05$. Results represent mean \pm SEM. 
tween left and right to separate vials. The tissue was moved immediately to liquid nitrogen and then stored at $-80^{\circ} \mathrm{C}$.

The homogenization of the tissue was done in cold $150 \mu \mathrm{l}$ of lysis buffer (10 mм HEPES, 2 mм EDTA, 2 mм EGTA, 0.5 mм DTT, 4\% protease inhibitor tablet cocktail from Roche, $1 \%$ phosphatase inhibitor from Sigma-Aldrich), using a glass Teflon homogenizer.

Gel electrophoresis and blotting. Equal volumes of brain extract diluted in sample buffer (2\% SDS, $20 \%$ glycerol, $0.12 \mathrm{~m}$ Tris, $\mathrm{pH}$ 6.8) were loaded to $10 \%$ polyacrylamide SDS-PAGE after boiling for $5 \mathrm{~min}$.

Each lane in the polyacrylamide gel was loaded with $8 \mu \mathrm{g}$ of protein separated at $30 \mathrm{~mA}$ for each gel, followed by blotting to a $0.45 \mu \mathrm{m}$ nitrocellulose membrane at $350 \mathrm{~mA}$ for $1 \mathrm{~h}$.

Blots were blocked with 5\% dry milk for Arc/Arg3.1and 5\% bovine serum albumin (BSA) for actin, extracellular signal-regulated kinase (ERK) and phospho-ERK (p-ERK) in Tris buffered saline Tween (TBST) incubated for $1 \mathrm{~h}$ at RT followed by incubation with primary antibody (Arc/Arg3.1 1:1000 mouse, BD Bioscience; Actin 1:3000 goat, Santa Cruz Biotechnology; ERK 1:1000, Cell Signaling Technologies; p-ERK cell signaling) containing 5\% BSA in TBST overnight with gentle shaking.

After three subsequent washing steps, blots were incubated for $1 \mathrm{~h}$ in RT with secondary antibody [donkey anti-goat (IgG), goat anti-mouse (IgG), Jackson ImmunoResearch Laboratories, 1:10,000) conjugated to HRP. After three washing steps with TBST, $10 \mathrm{~min}$ each, proteins were visualized by enhanced chemiluminescence EZ-ECL (Biological Industries) and quantified using a CCD camera (XRS Bio-Rad) and Quantity One software. The volume (area of the band * optical density) of each lane was quantified manually by the experimenter.

\section{Real-time PCR}

Total RNA was extracted from insular cortex specimens using TRI Reagent (Sigma) according to the manufacturer's instructions' including DNase I genomic DNA degradation step. Total RNA was reverse-transcribed using high capacity cDNA reverse transcription kit (Applied Biosystems). Realtime PCR analysis was performed using the PCR System STEP-ONE plus (PE Applied Biosystems). Q-PCR reactions were performed in a total volume of $10 \mu$ l on $10 \mathrm{ng}$ of cDNA using the following TaqMan assays (Applied Biosystems): activity-regulated cytoskeleton-associated protein, Arc/Arg3.1 (Rn00571208_g1), glyceraldehyde-3-phosphate dehydrogenase, GAPDH (Rn01775763_g1). Relative mRNA levels were calculated using the comparative $\mathrm{C}_{\mathrm{t}}$ method, using GAPDH as a normalizing gene.

\section{Statistical analysis}

The results are expressed as means \pm SEM. For statistical analysis ANOVA test with Scheffe post hoc test was used. In addition, Student's $t$ test for comparison between two groups was used. In cases where the results were not normally distributed, a-parametric tests were used; Mann-Whitney for comparing two groups and Kruskal Wallis for comparison between more than two groups.

To measure the stability of the clusters, a similarity measure between sets was used, partitioning around medoid (PAM) cluster analysis combined with the Jaccard coefficient.

\section{Results}

Novel taste learning does not induce Arc/Arg3.1 expression in the GC

To test Arc/Arg3.1 correlative levels with novel taste learning Wistar Hola rats were subjected to incidental taste learning paradigm with $0.1 \%$ saccharin or $0.3 \% \mathrm{NaCl}$ as the novel tastes. The mean number of Arc/Arg3.1-expressing cells in the GC was compared using immunohistochemistry. No significant difference was observed between $0.1 \%$ saccharin and water group (MannWhitney: $z=-0.23, p=0.87$; Fig. $1 c$ ). In addition, $0.3 \% \mathrm{NaCl}$ as novel taste had no significant effect on Arc/Arg3.1 modulation in the gustatory cortex compared with water group (Mann-Whitney: $z=$ $-0.80, p=0.52$; Fig. $1 d$ ).

To confirm the above results using another method, we used another set of animals for analysis of Arc/Arg3.1 levels using Western blot. This analysis did not show any significant differ- ences between saccharin and water $1 \mathrm{~h}$ following end of the drinking session (Mann-Whitney, $z=-0.96, p=0.38$; Fig. 1f). These results are in agreement with a recently published paper (Morin et al., 2011).

Arc/Arg3.1 mRNA is rapidly induced following learning episodes (Ramírez-Amaya et al., 2005), hence, Arc/Arg3.1 mRNA levels were analyzed shortly after the end of the drinking session. No significant differences in the expression of Arc/Arg3.1 mRNA following novel taste learning in the IC were detected (MannWhitney: $z=0.0, p=1.0$; Fig. $1 \mathrm{~g}$ ). These results are in agreement with another study which focused on Arc/Arg3.1 mRNA expression in the GC following novel taste learning in mice (MontagSallaz et al., 1999).

The ERK-MAPK is known as an upstream activator of Arc/ Arg3.1 (Ploski et al., 2008) and was also found to be correlated with and necessary for novel taste learning (Berman et al., 1998; Belelovsky et al., 2005). We thus measured ERK phosphorylation in the gustatory cortex following novel taste learning and found significant induction $20 \mathrm{~min}$ after end of the drinking session (MannWhitney, $z=-2.12, p=0.03$; Fig. $1 h$ ), in agreement with previous studies (Berman et al., 1998; Belelovsky et al., 2005).

Interestingly, we could not detect significant changes in Arc/ Arg3.1 levels in correlation with novel taste learning in the GC. Because the differential contribution of each GC hemisphere to novel taste learning is unknown, we tested the effect of novelty on the hemispheres separately.

\section{Novel taste learning induces lateralization of Arc/Arg3.1 protein in the insular cortex}

To evaluate the left-right dynamics in the GC and its correlation to novel taste learning, each hemisphere was measured separately, and lateralization index was calculated for each animal as follows:

|(Arc levels in left GC - Arc levels in right GC)/

(Total Arc levels)|.

Using the above equation we did not assume one fixed hemisphere is more active than the other.

Novel taste learning changed the dynamics of Arc/Arg3.1 levels between hemispheres as measured by the lateralization index; whereas water drinking induced relatively small hemispheric lateralization, saccharin induced strong asymmetry-approximately six times higher asymmetrical distribution of Arc/Arg3.1 in the left-right axis, as measured by immunohistochemistry (Mann-Whitney: $z=-3.24, p=0.00031$; Fig. $2 b$ ).

In a similar way, another lateralization index of another novel taste $0.3 \% \mathrm{NaCl}$ was compared with a group of animals which received water. A significant difference was observed between lateralization index values of the two groups (Mann-Whitney: $z=-2.39, p=0.017$; Fig. $2 d$ ), indicating that the lateralization is not unique to a given taste per se but is related to the novelty property of a taste.

We found no preference of lateralization toward any specific hemisphere, the distribution of dominant sides in these animals seems to be equal: six animals were right sided and five animals were left sided, indicating lateralization at individual level (data not shown).

To test our hypothesis that lateralization in the GC is higher following novel taste learning, using another method, we performed another experiment and Western blot analysis of insular cortex homogenates to compare the lateralization index of animals exposed to novel $0.1 \%$ saccharin or water $1 \mathrm{~h}$ following drinking session. Lateralization index of Arc/Arg3.1 levels in the 
a Arc lateralization index $=\frac{\text { (left GC-right GC) }}{\text { (left GC+right GC) }}$

b

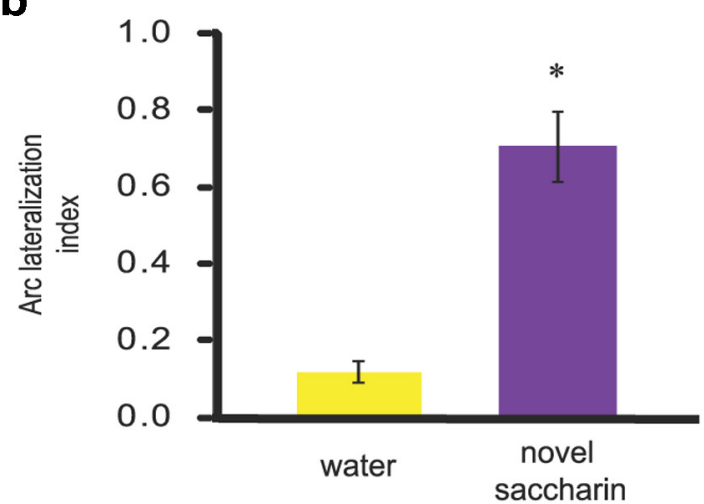

d

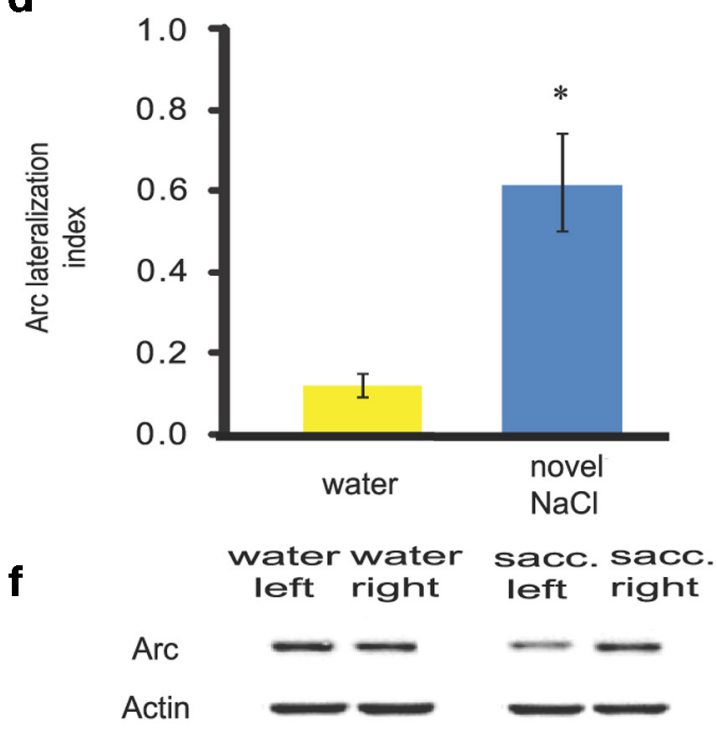

c water

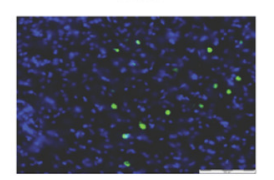

novel saccharin
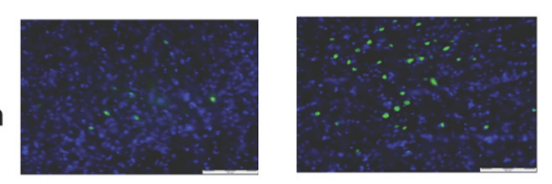

e

left
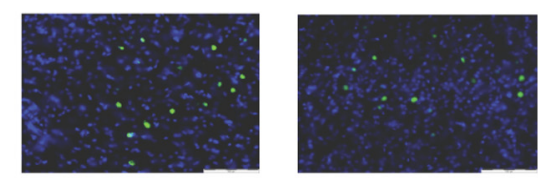

novel

$\mathrm{NaCl}$
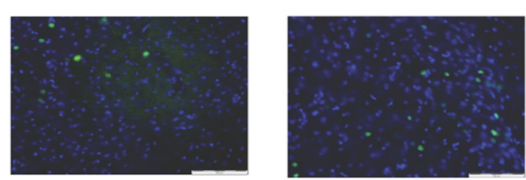

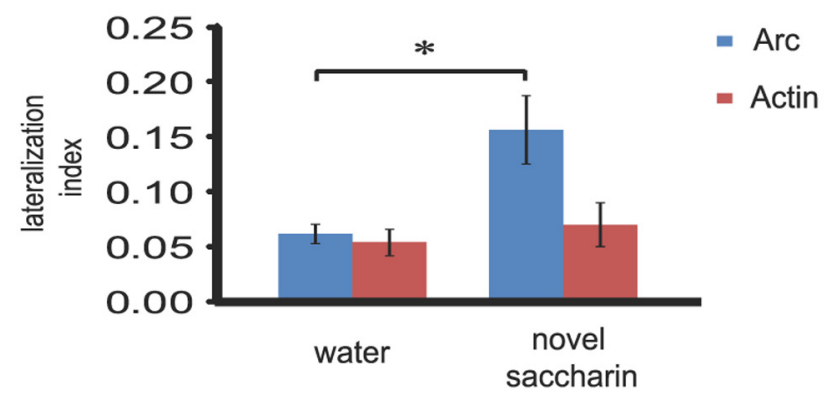

Figure 2. Novel taste learning induces lateralization in the insular cortex. $\boldsymbol{a}$, Lateralization index (LI) formula. $\boldsymbol{b}, \mathrm{Ll}$ of Arc/Arg 3.1 is higher in the gustatory cortex $1 \mathrm{~h}$ following novel taste learning with saccharin, as measured by immunohistochemistry. Rats drank $0.1 \%$ saccharin as a novel taste $(n=8)$ or water $(n=7)$ as a familiar taste. ${ }^{*} p<0.05$. c, Immunofluorescence representative images (blue, Hoechst nuclear staining; green, Arc/Arg3.1 protein). Scale bar, $100 \mu \mathrm{m} . \boldsymbol{d}, \mathrm{Ll}$ of Arc/Arg3.1 is higher in the gustatory cortex $1 \mathrm{~h}$ following novel taste learning with NaCl, as measured by immunohistochemistry. Rats drank $0.3 \% \mathrm{NaCl}$ as a novel taste $(n=3)$ or water $(n=7)$ as a familiar taste. ${ }^{*} p<0.05$. $\boldsymbol{e}$, Immunofluorescence representative images (blue, Hoechst nuclear staining; green, Arc/Arg3.1 protein). Scale bar, $100 \mu \mathrm{m}$. f, Higher asymmetrical levels of Arc/Arg3.1 but not actin in the gustatory cortex $1 \mathrm{~h}$ following novel taste learning with saccharin as measured by Western blot. Rats drank $0.1 \%$ saccharin as a novel taste $(n=7)$ or water $(n=7)$ as a familiar taste. Top, Representative immune-blots of Arc/Arg3.1and Actin. ${ }^{*} p=0.01$. Results represent mean \pm SEM.

saccharin group was significantly higher than that of the water group (Mann-Whitney, $z=-2.88, p=0.002$ ). No significant differences were found in actin (taken as a control protein) lateralization between water and saccharin groups (Mann-Whitney, $z=-0.53, p=0.65$; Fig. $2 f)$.
Analysis of the lateralization index of Arc/Arg3.1 mRNA immediately following the drinking session did not show any significant difference between novel $0.1 \%$ saccharin and water groups (data not shown; water $0.148 \pm 0.049$; saccharin $0.166 \pm 0.048$; Mann-Whitney, $z=-0.32, p=0.818)$. 
Taste familiarity is inversely correlated to lateralization of Arc/Arg3.1 protein levels in the GC

To better understand the interaction between novelty and lateralization, and to introduce another familiar taste other then water, four different levels of familiarity with taste were examined: one exposure to $0.1 \%$ saccharin (representing novel taste), two exposures to $0.1 \%$ saccharin (representing a novel to weakly familiar taste), $25 \mathrm{~d}$ of $0.1 \%$ saccharin familiarization (representing a more robustly familiar taste), and continuous exposure to water (representing the ultimate familiar taste; Fig. $3 b$ ). Here, an inverse correlation between novelty and lateralization was observed with significant effect of the familiarization to the taste on the lateralization index (main effect of the group, ANOVA, $\left.F_{(3,28)}=10.26, p=0.00016\right)$, nonsignificant trend for reduction in lateralization after two times saccharin compared with novel taste (Scheffe post hoc, $p=0.079$ ), and a significant decrease in lateralization after $25 \mathrm{~d}$ of familiarization compared with novel taste (Scheffe post hoc, $p=0.012$ ). Moreover, no significant difference in lateralization was observed between the ultimate familiar taste water and $25 \mathrm{~d}$ of saccharin familiarization (Scheffe post hoc, $p=0.58$ ), meaning they are equal from the lateralization point of view. Scheffe post hoc test showed, similarly to Figure 2, that novel taste learning induces significantly stronger lateralization/asymmetry for Arc/Arg3.1 protein levels in the GC compared with the water group (Scheffe post hoc, $p=0.00024$ ).

In parallel to the decrease in LI with the familiarization of the taste (Fig. $3 b$ ) we found no significant difference in the total (combined left and right hemispheres) number of Arc/Arg3.1expressing cells in the nuclear/somatic area among the four groups (number of Arc expressing cells: novel $0.1 \%$ saccharin $17.1 \pm 5.76$, two times $0.1 \%$ saccharin $19.60 \pm 7.92,25 \mathrm{~d} 0.1 \%$ saccharin $11.41 \pm 1.66$ and water $10.64 \pm 1.65$, Kruskal-Wallis test: $\chi^{2}=0.756, p=0.86$ ).

To test whether the lateralization is specific to the GC, we calculated the lateralization index in another cortical area, somatosensory cortex (SS1J), in the same four groups and on the same slices analyzed for the GC area. Because the results are not normally distributed, we performed a nonparametric KruskalWallis test, and found no difference between groups $\left(\chi^{2}=0.57\right.$, $p=0.13$; Fig. $3 d$ ). Moreover, there is no significant difference between water and saccharin groups (Mann-Whitney: $z=$ $-1.04, p=0.34)$.

\section{Animals unilaterally injected with the protein synthesis inhibitor anisomycin display bimodal distribution of memory performance in CTA}

Because Arc/Arg3.1 is considered a "master regulator" of protein synthesis-dependent forms of synaptic plasticity and because Arc/Arg3.1 hemispheric lateralization is equally and randomly distributed among the novel taste learning animals, we decided to examine the dependence of conditioned taste aversion memory on protein synthesis inhibition in one hemisphere (Fig. 4b).

Assuming lateralization is a cortical function, and considering Arc/Arg3.1 protein expression as an indicator for neuronal activity and plasticity, and because of the dependence of CTA memory formation on protein synthesis (Rosenblum et al., 1993), we used anisomycin to test the biochemical lateralization that correlates with taste learning. CTA is considered a highly robust behavioral paradigm with small SDs and marked differences between treatment groups (Rosenblum et al., 1993; Moguel-González et al., 2008). We found these properties of CTA ideal for our hypothesis that unilateral inhibition of protein synthesis will have a binarylike effect on animals' performance, i.e., strong memory preser- vation or memory impairment, depending on the dominance of the pharmacologically manipulated hemisphere.

Animals were divided into two groups: "model group" composed of animals injected with anisomycin or vehicle to both hemispheres and "test group" composed of animals injected with anisomycin to left hemisphere, vehicle to right hemisphere, and vice versa.

We imposed PAM clustering on the aversion index for both groups and compared the similarity in distribution between the groups using cluster analysis. The stability of each cluster was assessed by Jaccard coefficient bootstrap distribution (Hennig, 2007). Values $>0.85$ were considered as indicating high cluster stability. The two clusters chosen for model and test groups are highly stable (bootstrap cluster $>0.97$ for both). Moreover, increasing number of clusters to three produced less stable bootstrap clusters with a lowest value of 0.55 , and in four clusters the lowest stability is 0.78 (data not shown), indicating that the best clustering arrangement is with two clusters, where approximately equal distribution of animals from model and test groups is present in each cluster in accordance with our initial hypothesis. To define animal's naive aversion to saccharin, we tested aversion index for the choice between novel $0.1 \%$ saccharin and water for $20 \mathrm{~min}$. The average aversion index was found to be $0.58(58 \%)$ and the median of this group is $0.60(60 \% ; n=10$ rats, data not shown). This $\sim 0.6$ native aversion index for $0.1 \%$ saccharin is very similar to the observed aversion index for Wistar Hola animals (Stehberg et al., 2011) and can serve as a cutoff border separating between aversive memory $(>0.6)$ and absence of memory $(<0.6)$.

\section{Discussion}

The main finding of this study is that novel taste learning induces cortical lateralization at the molecular level and that there are clear relationships between the novel to familiar axis and the degree of this lateralization. These results describe biochemical changes that correlate with lateralization in the mammalian cortex following learning.

Specifically, novel and familiar tastes were correlated with different patterns of Arc/Arg3.1 protein levels in one versus contra lateral GC hemispheres. Second, Arc/Arg3.1 hemispheric lateralization decreased as novel taste became familiar. Third, injection of protein synthesis inhibitor anisomycin randomly into one hemisphere before CTA acquisition affects memory performance in a bimodal manner, i.e., either intact memory or strong memory impairment. Fourth, in parallel to the lateralized levels of Arc/Arg3.1 in correlation with novel taste, there was no change in total Arc/Arg3.1nuclear or somatic expression in both hemispheres following novel taste learning in accordance with recently published findings (Morin et al., 2011).

IEGs are strongly regulated following learning in many behavioral paradigms (for review, see Okuno, 2011). Interestingly, sampling $0.1 \%$ saccharin, which creates strong long-term memory trace (Gal-Ben-Ari and Rosenblum, 2011), has no effect on c-fos levels following novel taste learning as compared with water in the GC. However, c-fos, is differentially expressed following novel taste learning in subpopulation of GABAergic cells in the GC (Doron and Rosenblum, 2010). High concentration of saccharin $(0.5 \%)$ induce detectable levels of c-fos expression in the GC (Koh et al., 2003; Bernstein and Koh, 2007).

Lateralization of taste and odor processing has been reported in different organisms along the evolutionary tree. In humans, lateralization of the inferior insula, the primary gustatory cortex, was observed using fMRI after exposure of subjects to five 
a

two times $0.1 \%$ saccharin

after $1 \mathrm{hr}$

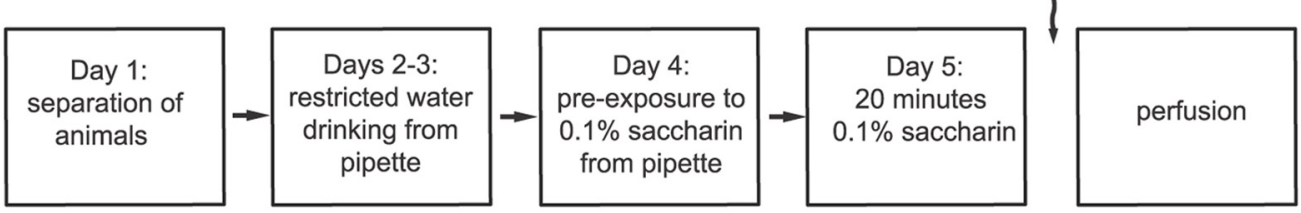

25 days of $0.1 \%$ saccharin

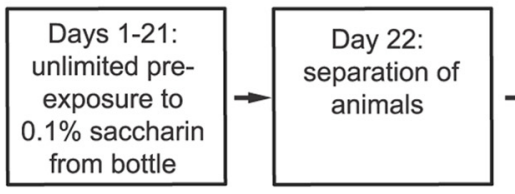

b

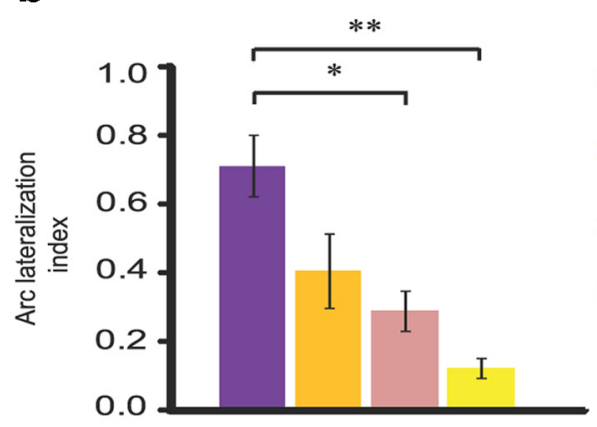

d

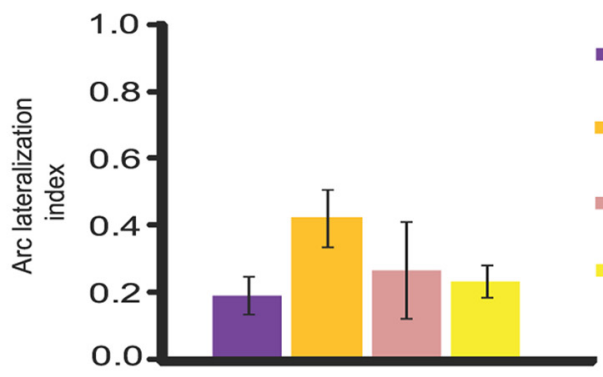

novel

- saccharin

saccharin 2

times

saccharin 25 days

water

novel

saccharin

saccharin 2

times

saccharin

25 days

water

after $1 \mathrm{hr}$

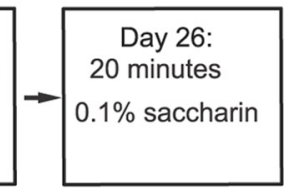

left

C

novel saccharin
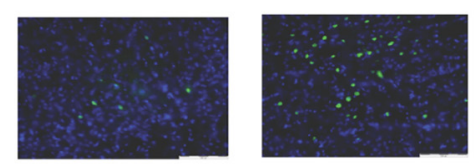

saccharin 2 times
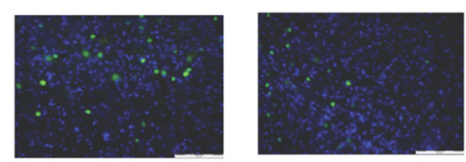

saccharin 25 days
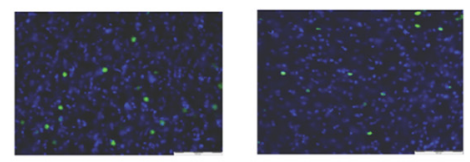

water

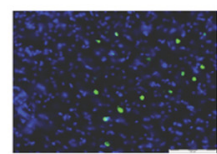

left

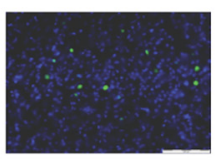

e

novel saccharin

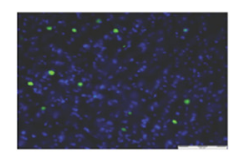

right

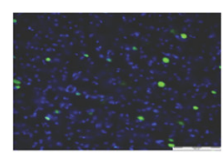

saccharin

2 times
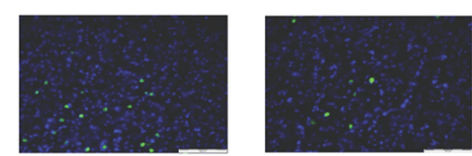

saccharin 25 days
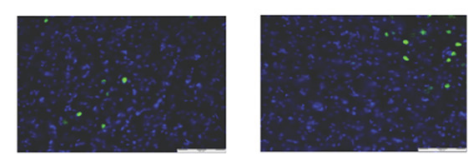

water
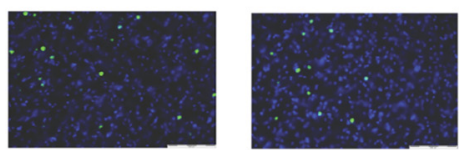

Figure 3. Familiarity of taste is inversely correlated to lateralization index for Arc/Arg3.1in the gustatory cortex. $\boldsymbol{a}$, Schematic representation of the behavioral paradigms for familiarization with taste. $\boldsymbol{b}$, Familiarization with taste decreased the LI in the gustatory cortex. Four levels of familiarity were assessed-novel $0.1 \%$ saccharin $(n=8)$, two times $0.1 \%$ saccharin $(n=7), 25 \mathrm{~d} 0.1 \%$ saccharin $(n=6)$ and water $(n=7)$ as a familiar taste. ${ }^{*} p<0.05 ;{ }^{* *} p<0.01$. c, Immunofluorescence representative images (blue, Hoechst nuclear staining; green, Arc/Arg3.1 protein). Scale bar, $100 \mu \mathrm{m}$. $\boldsymbol{d}$, Familiarization with taste did not affect the lateralization in the somatosensory cortex as assessed in the four paradigms of familiarization described in (b). $p>0.05$. $\boldsymbol{e}$, Immunofluorescence representative images (blue, Hoechst nuclear staining; green, Arc/Arg3.1 protein). Scale bar, $100 \mu \mathrm{m}$. Results represent mean \pm SEM. 


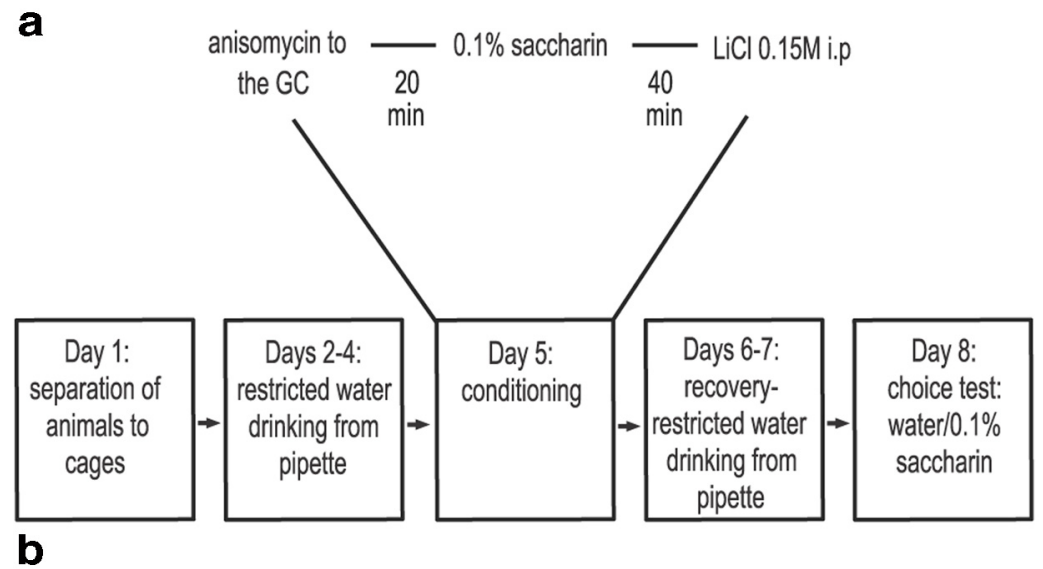

b

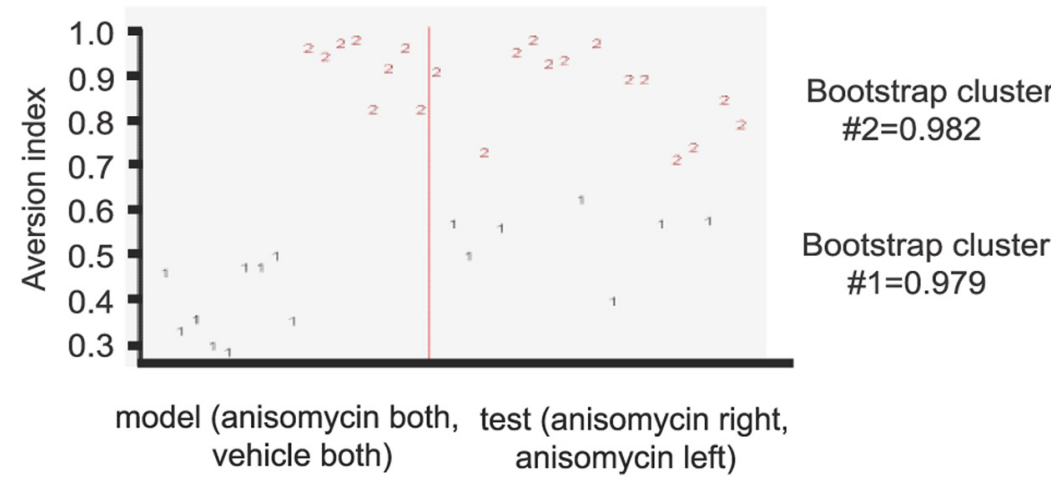

Figure 4. Unilateral injection of anisomycin affects taste memory in a bimodal like manner. $\boldsymbol{a}$, Schematic representation of the behavioral protocol for uni/bilateral injection of anisomycin or vehicle to the GC before CTA. $\boldsymbol{b}$, PAM clustering for aversion index to saccharin according to anisomycin treatment. Two highly stable clusters were detected when combining two model groups, bilateral anisomycin and bilateral vehicle $(n=17)$ and two test groups, left hemisphere injected with anisomycin and the right with vehicle, or vice versa $(n=20)$. The red line separates the test and model groups.

different tastes. The observed lateralization was correlated to handedness, left-handed subjects showed right inferior insula activation, whereas right-handed subjects showed left inferior insula activation (Faurion et al., 1999). This result indicates that symmetrical stimuli on the tongue resulted in asymmetrical brain activity in the cortex, similarly to Arc/Arg3.1 protein expression in our study. The lateralization of Arc/Arg3.1 at protein level was not observed at the mRNA level. This may suggest that the difference in the lateralization is a posttranscription processes.

Importantly, one interpretation of the observed lateralization of Arc/Arg3.1 protein expression following novel taste consumption (Fig. 2) is that unilateral sensory response from one-half of the tongue is responsible for the lateralization observed in the GC located in the opposite hemisphere. This possibility is not likely, because long-term familiarization to saccharin ( $25 \mathrm{~d}$; Fig. 3 ) reduced significantly the lateralization index, indicating that the lateralization observed in the group exposed to saccharin as a novel taste is not simply a sensory response for taste, but an active process modulated as the familiarity of the taste increases. In rats, ipsilateral interactions between the GC and the parabrachial nucleus or amygdala are necessary and sufficient for the formation of CTA memory (Gallo and Bures, 1991; Bielavska and Roldan, 1996).

In terrestrial slug Limax it was inferred from unilateral ablation experiments that the odor-aversion memory stored unilaterally in one side of the procerebrum and that the storage side is randomly determined (Matsuo et al., 2010). This paper showed that the unilateral storage of the memory is equally distributed in the population, meaning a $50 \%$ chance to impair the memory by random inactivation. The authors suggested that the dominant procerebrum is not innately predestined in each slug but has flexible properties depending on the olfactory pathway. Interestingly, the memory is stored unilaterally in the procerebrum for at least 1 week without transfer of the memory to the other side.

In fruit flies the bilateral presence of a brain structure named the "asymmetrical body" in a small proportion of wild-type flies prevents long-term memory formation but preserves short-term memory for odor-electric shock association. Animals with an asymmetrical body located unilaterally have normal long-term memory (Pascual et al., 2004). The authors concluded that brain asymmetry may be required for formation or retrieval of longterm memory. In our study, the observed Arc/Arg3.1 protein asymmetry in the GC might be a nonbinary analog to the bilateral presence or the absence of the asymmetric body in fruit flies, raising the possibility that the magnitude of Arc/ Arg3.1 lateralization in the GC following novel taste may affect long-term memory formation.

The lateralization magnitude of Arc/ Arg3.1 is modulated by repeated exposures to the taste (Fig. $3 b$ ); one pre-exposure or long periods of familiarization to saccharin ( $25 \mathrm{~d}$ of drinking) reduced the average lateralization index. Importantly, after $25 \mathrm{~d}$ of familiarization with saccharin the lateralization index decreased and was similar to that of rats which consumed water, but different from the rats which consumed saccharin as a novel taste. The long-lasting decrease in GC lateralization reflects left-right dynamics at circuit level starting with large Arc/Arg3.1 asymmetry between hemispheres when the taste is novel and diverted toward symmetry as familiarity increases. In a study by Morin et al. (2011) the authors quantified Arc/Arg3.1 specifically in dendrites and showed increase in Arc/ Arg3.1 expression as the novel taste (saccharin) became more familiar (saccharin with several pre-exposures). This change was not observed in the nuclear/somatic area when they compared novel taste and familiar taste.

Novelty detection in taste learning is correlated with increase in acetylcholine release in the insular cortex (Miranda et al., 2003); moreover, familiarization with saccharin decreased the amount of the released acetylcholine. Arc/Arg3.1 gene expression is downstream to muscarinic acetylcholine receptor stimulation (Teber et al., 2004), raising the possibility that acetylcholine activation together with other cellular processes (Shepherd and Bear, 2011) modulate Arc/Arg3.1 expression lateralization in the GC following novel taste learning.

Latent inhibition of CTA depends on the GC (Rosenblum et al., 1997; Roman and Reilly, 2007; Roman et al., 2009) and involves pre-exposure of animals to unfamiliar taste before conditioning of the animals with the same taste coupled with malaise-inducing agent. The result of latent inhibition is reduction in the aversion of animals to the taste, indicating that the strength of the memory for CTA depends on the degree of the familiarity with the taste (Gal-Ben-Ari and Rosenblum, 2011). 
In relation to human pathologies, latent inhibition paradigm can be used to estimate attention processes and attention deficits in cognitive abnormalities such as schizophrenia (Weiner, 1990; Gray et al., 1995). Interestingly, reduction in lateralization may play a critical role in the development of schizophrenia (Oertel et al., 2010; Freitag et al., 2013). In addition, reduction in language lateralization is associated with auditory hallucinations in schizophrenic patients (Ocklenburg et al., 2013).

Formation of long-term memory, but not short-term memory, requires synthesis of new proteins during a critical time window following the acquisition phase. This was shown in many behavioral paradigms by application of protein synthesis inhibitors that impaired long-term memory formation (Davis and Squire, 1984; Goelet et al., 1986; Rosenblum et al., 1993). Specifically, Arc/Arg3.1 was found to be strongly related to synaptic plasticity processes that are dependent on protein synthesis (Bramham et al., 2010), and Arc/Arg3.1 expression is linked to plasticity inducing stimuli in active brain networks (Guzowski et al., 2005; Ramírez-Amaya et al., 2005; Miyashita et al., 2009). Therefore, to examine whether Arc/Arg3.1 protein lateralization in the GC is necessary for long-term taste aversion memory, protein synthesis was inhibited unilaterally or bilaterally (Rosenblum et al., 1993) by local injection of the protein synthesis inhibitor anisomycin into the GC (Fig. 4).

The distribution of aversion index in unilaterally injected animals resembled the distribution of animals injected bilaterally with anisomycin or vehicle in a manner which has binary-like properties, indicating that single hemisphere inhibition can affect memory unequally: either strong memory impairment or memory preservation. The fact that a two-cluster arrangement has the highest stability indicates that the test groups (injection of anisomycin to one hemisphere and vehicle to the other) are embedded into the model groups (bilateral injection of either anisomycin or vehicle) to produce together a highly stable distribution of two clusters, where one cluster represents animals with low aversion index meaning impaired memory, and the second cluster of animals with high aversion index, animals with intact memory.

This result suggests that the lateralized protein synthesis inhibition has a functional effect on memory consolidation and that each hemisphere is differentially involved in taste memory consolidation. The native aversion index of naive Wistar Hola rats for $0.1 \%$ saccharin is $\sim 0.6$. This observation was repeated by others (Stehberg et al., 2011). Although the aversion indices of test group animals belong to cluster number 1 (seven animals belong to this group with an average aversion index of 0.54 ), these values are higher than that of model group animals which belong to cluster number 1 (nine animals belong to this group with an average aversion index of 0.40 ), both groups can be considered as animals with impaired CTA memory because their aversion index is 0.6 and below.

For the test group which belongs to cluster number 1, the aversion index decreased by $40 \%$ to 0.54 compared with model group belonging to cluster number 2 , and the aversion index of this group is higher by $\sim 15 \%$ compared with the model group which belongs to cluster number 1 . This indicates that each hemisphere contributes differentially and asymmetrically to memory consolidation.

These results suggest that the nondominant hemisphere is involved to some extent in memory consolidation, but the dependence on protein synthesis, like Arc/Arg3.1 protein expression, is strongly asymmetric with differential contribution of the protein synthesis in each hemisphere to memory consolidation. Interestingly, brightness discrimination in rats involved lateralized pro- tein synthesis rates in the hippocampus (Lossner and Matthies, 1984). One possible result of such lateralized protein synthesis rates is that unilateral inhibition can affect memory performance unequally.

The cluster analysis imposed on the aversion index data for all four groups represents a different point of view about interpretation of unilateral manipulation by pharmacology. Here the focus is not on the average result for unilaterally treated groups like in other cases (Gallo and Bures, 1991; Matsuo et al., 2010) but on the distribution of animals compared with the model group which was injected bilaterally with anisomycin or vehicle. The averages for unilateral manipulations compared with averages of bilateral manipulations are misleading, since they hide the possibility of individual lateralization and bimodal or strong asymmetric effect on performance. The cluster analysis strategy leads to a substantially different conclusion on the effect of the unilateral manipulation on memory performance.

What might be the role of lateralization or its advantage? The biggest advantage in lateralization of cognitive functions is to enhance the capacity of the brain by releasing the nondominant hemisphere to perform other tasks, promoting specialization of the dominant hemisphere in particular tasks (Vallortigara, 2006). Another possible advantage of lateralization is enhancement of function in cognitive tasks which require simultaneous use of left and right sides for different purposes. In chicks it was shown that the performance of lateralized individuals was better compared with the nonlateralized individuals in a learning paradigm involving finding food and being vigilant for predators task (Rogers et al., 2004).

Further study will try to track the lateralization in other brain regions involved in taste processing to better understand the origin of lateralization along the taste pathway and in addition, to broaden the understanding of molecular and cellular processes other than Arc/Arg3.1 that are involved in hemispheric lateralization during novel taste memory consolidation.

Our results link biochemical changes and specifically Arc/ Arg3.1 protein expression together with lateralization in the mammalian cortex. The lateralization observed during novel taste memory may represent a new systemic output for novelty processing and emphasis of the fundamental circuit difference in processing of familiar and novel taste.

\section{References}

Barki-Harrington L, Elkobi A, Tzabary T, Rosenblum K (2009) Tyrosine phosphorylation of the $2 \mathrm{~B}$ subunit of the NMDA receptor is necessary for taste memory formation. J Neurosci 29:9219-9226. CrossRef Medline

Belelovsky K, Elkobi A, Kaphzan H, Nairn AC, Rosenblum K (2005) A molecular switch for translational control in taste memory consolidation. Eur J Neurosci 22:2560-2568. CrossRef Medline

Belelovsky K, Kaphzan H, Elkobi A, Rosenblum K (2009) Biphasic activation of the mTOR pathway in the gustatory cortex is correlated with and necessary for taste learning. J Neurosci 29:7424-7431. CrossRef Medline

Berman DE, Hazvi S, Rosenblum K, Seger R, Dudai Y (1998) Specific and differential activation of mitogen-activated protein kinase cascades by unfamiliar taste in the insular cortex of the behaving rat. J Neurosci 18 : 10037-10044. Medline

Bernstein IL, Koh MT (2007) Molecular signaling during taste aversion learning. Chem Senses 32:99-103. CrossRef Medline

Bielavska E, Roldan G (1996) Ipsilateral connections between the gustatory cortex, amygdala and parabrachial nucleus are necessary for acquisition and retrieval of conditioned taste aversion in rats. Behav Brain Res 81:25-31. CrossRef Medline

Bramham CR, Alme MN, Bittins M, Kuipers SD, Nair RR, Pai B, Panja D, Schubert M, Soule J, Tiron A, Wibrand K (2010) The Arc of synaptic memory. Exp Brain Res 200:125-140. CrossRef Medline

Chowdhury S, Shepherd JD, Okuno H, Lyford G, Petralia RS, Plath N, Kuhl 
D, Huganir RL, Worley PF (2006) Arc/Arg3.1 interacts with the endocytic machinery to regulate AMPA receptor trafficking. Neuron 52:445459. CrossRef Medline

Davis HP, Squire LR (1984) Protein synthesis and memory: a review. Psychol Bull 96:518-559. CrossRef Medline

Doron G, Rosenblum K (2010) c-fos expression is elevated in GABAergic interneurons of the gustatory cortex following novel taste learning. Neurobiol Learn Mem 94:21-29. CrossRef Medline

Faurion A, Cerf B, Van De Moortele PF, Lobel E, Mac Leod P, Le Bihan D (1999) Human taste cortical areas studied with functional magnetic resonance imaging: evidence of functional lateralization related to handedness. Neurosci Lett 277:189-192. CrossRef Medline

Freitag MT, Van Bruggen T, Fritzsche KH, Henze R, Brunner R, Parzer P, Resch F, Stieltjes B (2013) Reduced lateralization in early onset schizophrenia. Neurosci Lett 537:23-28. CrossRef Medline

Gal-Ben-Ari S, Rosenblum K (2011) Molecular mechanisms underlying memory consolidation of taste information in the cortex. Front Behav Neurosci 5:87. CrossRef Medline

Gallo M, Bures J (1991) Acquisition of conditioned taste aversion in rats is mediated by ipsilateral interaction of cortical and mesencephalic mechanisms. Neurosci Lett 133:187-190. CrossRef Medline

Goelet P, Castellucci VF, Schacher SKE (1986) The long and the short of long-term memory:a molecular framework. Nature 6:419-422. CrossRef Medline

Gray JA, et al. (1995) The role of mesolimbic dopaminergic and retrohippocampal afferents to the nucleus accumbens in latent inhibition: implications for schizophrenia. Behav Brain Res 71:19-31. CrossRef Medline

Guzowski JF, Timlin JA, Roysam B, McNaughton BL, Worley PF, Barnes CA (2005) Mapping behaviorally relevant neural circuits with immediateearly gene expression. Curr Opin Neurobiol 15:599-606. CrossRef Medline

Hennig C (2007) Cluster-wise assessment of cluster stability. Comput Stat Data Anal 52:258-271. CrossRef

Iglói K, Doeller CF, Berthoz A, Rondi-Reig L, Burgess N (2010) Lateralized human hippocampal activity predicts navigation based on sequence or place memory. Proc Natl Acad Sci U S A 107:14466-14471. CrossRef Medline

Koh MT, Wilkins EE, Bernstein IL (2003) Novel tastes elevate c-fos expression in the central amygdala and insular cortex: implication for taste aversion learning. Behav Neurosci 117:1416-1422. CrossRef Medline

Lössner B, Matthies H (1984) Changes in the incorporation of $\left[{ }^{3} \mathrm{H}\right]$ leucine into proteins of rat hippocampus subregions during the acquisition of a brightness discrimination are lateralized. Biomed Biochim Acta 43: 1405-1415. Medline

Matsuo R, Kawaguchi E, Yamagishi M, Amano T, Ito E (2010) Unilateral memory storage in the procerebrum of the terrestrial slug Limax. Neurobiol Learn Mem 93:337-342. CrossRef Medline

Menon V, Uddin LQ (2010) Saliency, switching, attention and control: a network model of insula function. Brain Struct Funct 214:655-667. CrossRef Medline

Merhav M, Rosenblum K (2008) Novel taste is protein-synthesis dependent facilitation of taste memory acquisition by experiencing previous novel taste is protein-synthesis dependent. Learn Mem 14:501-507. CrossRef Medline

Miranda MI, Ferreira G, Ramírez-Lugo L, Bermúdez-Rattoni F (2003) Role of cholinergic system on the construction of memories: taste memory encoding. Neurobiol Learn Mem 80:211-222. CrossRef Medline

Miyashita T, Kubik S, Haghighi N, Steward O, Guzowski JF (2009) Rapid activation of plasticity-associated gene transcription in hippocampal neurons provides a mechanism for encoding of one-trial experience. J Neurosci 29:898-906. CrossRef Medline

Moguel-González M, Gómez-Palacio-Schjetnan A, Escobar ML (2008) Neurobiology of learning and memory BDNF reverses the CTA memory deficits produced by inhibition of protein synthesis. Neurobiol Learn Mem 90:584-587. CrossRef Medline

Montag-Sallaz M, Welzl H, Kuhl D, Montag D, Schachner M (1999) Novelty induced increased expression of immediate early genes c-fos and arg 3.1 in the mouse brain. J Neurobiol 38:234-246. CrossRef Medline

Morin JP, Quiroz C, Mendoza-Viveros L, Ramirez-Amaya V, BermudezRattoni F (2011) Familiar taste induces higher dendritic levels of activity-regulated cytoskeleton-associated protein in the insular cortex than a novel one. Learn Mem 18:610-616. CrossRef Medline

Ocklenburg S, Westerhausen R, Hirnstein M, Hugdahl K (2013) Auditory hallucinations and reduced language lateralization in schizophrenia: a meta-analysis of dichotic listening studies. J Int Neuropsychol Soc: 19: 410-418. CrossRef Medline

Oertel V, Knöchel C, Rotarska-Jagiela A, Schönmeyer R, Lindner M, Van De Ven V, Haenschel C, Uhlhaas P, Maurer K, Linden DE (2010) Reduced laterality as a trait marker of schizophrenia: evidence from structural and functional neuroimaging. J Neurosci 30:2289-2299. CrossRef Medline

Okuno H (2011) Regulation and function of immediate-early genes in the brain: beyond neuronal activity markers. Neurosci Res 69:175-186. CrossRef Medline

Pascual A, Huang K, Neveu J, Préat T (2004) Neuroanatomy: brain asymmetry and long-term memory. Nature 427:605-606. CrossRef Medline

Plath N, Ohana O, Dammermann B, Errington ML, Schmitz D, Gross C, Mao $\mathrm{X}$, Engelsberg A, Mahlke C, Welzl H, Kobalz U, Stawrakakis A, Fernandez E, Waltereit R, Bick-Sander A, Therstappen E, Cooke SF, Blanquet V, Wurst W, Salmen B, et al. (2006) Arc/Arg3.1 is essential for the consolidation of synaptic plasticity and memories. Neuron 52:437-444. CrossRef Medline

Ploski JE, Pierre VJ, Smucny J, Park K, Monsey MS, Overeem KA, Schafe GE (2008) The activity-regulated cytoskeletal-associated protein (Arc/Arg3.1) is required for memory consolidation of Pavlovian fear conditioning in the lateral amygdala. J Neurosci 28:12383-12395. CrossRef Medline

Ramírez-Amaya V, Vazdarjanova A, Mikhael D, Rosi S, Worley PF, Barnes CA (2005) Spatial exploration-induced Arc mRNA and protein expression: evidence for selective, network-specific reactivation. J Neurosci 25:1761-1768. CrossRef Medline

Rogers LJ, Zucca P, Vallortigara G (2004) Advantages of having a lateralized brain. Proc Biol Sci 6:S420-422. CrossRef Medline

Roman C, Reilly S (2007) Effects of insular cortex lesions on conditioned taste aversion and latent inhibition in the rat. Eur J Neurosci 26:26272632. CrossRef Medline

Roman C, Lin JY, Reilly S (2009) Conditioned taste aversion and latent inhibition following extensive taste pre-exposure in rats with insular cortex lesions. Brain Res 1259:68-73. CrossRef Medline

Rosenblum K, Meiri N, Dudai Y (1993) Taste memory: the role of protein synthesis in gustatory cortex. Behav Neural Biol 59:49-56. CrossRef Medline

Rosenblum K, Berman DE, Hazvi S, Lamprecht R, Dudai Y (1997) NMDA receptor and the tyrosine phosphorylation of its $2 \mathrm{~B}$ subunit in taste learning in the rat insular cortex. J Neurosci 17:5129-5135. Medline

Shema R, Sacktor TC, Dudai Y (2007) Rapid erasure of long-term memory associations in the cortex by an inhibitor of PKM zeta. Science 317: 951-953. CrossRef Medline

Shepherd JD, Bear MF (2011) New views of Arc, a master regulator of synaptic plasticity. Nat Neurosci 14:279-284. CrossRef Medline

Stehberg J, Simon F (2011) Involvement of the insular cortex in retention of conditioned taste aversion is not time dependent. Neurobiol Learn Mem 95:14-18. CrossRef Medline

Stehberg J, Moraga-Amaro R, Simon F (2011) The role of the insular cortex in taste function. Neurobiol Learn Mem 96:130-135. CrossRef Medline

Teber I, Köhling R, Speckmann EJ, Barnekow A, Kremerskothen J (2004) Muscarinic acetylcholine receptor stimulation induces expression of the activity-regulated cytoskeleton-associated gene (ARC). Brain Res Mol Brain Res 121:131-136. CrossRef Medline

Tulving E, Markowitsch HJ, Craik FE, Habib R, Houle S (1996) Novelty and familiarity activations in PET studies of memory encoding and retrieval. Cereb Cortex 6:71-79. CrossRef Medline

Vallortigara G (2006) The evolutionary psychology of left and right: costs and benefits of lateralization. Dev Psychobiol 48:418-427. CrossRef Medline

Weiner I (1990) Neural substrates of latent inhibition: the switching model. Psychol Bull 108:442-461. CrossRef Medline

Yefet K, Merhav M, Kuulmann-Vander S, Elkobi A, Belelovsky K, JacobsonPick S, Meiri N, Rosenblum K (2006) Different signal transduction cascades are activated simultaneously in the rat insular cortex and hippocampus following novel taste learning. Eur J Neurosci 24:14341442. CrossRef Medline 